Kessel, P. van, Triemstra, M., Boer, D. de, Plass, A.M. Meten van uitkomsten van zorg met PROMs. Nederlands Tijdschrift voor Evidence Based Practice: 2016, 13(2), 8-10

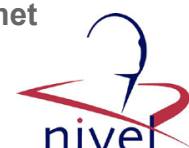

\begin{tabular}{|l|l|}
\hline $\begin{array}{l}\text { Postprint } \\
\text { Version }\end{array}$ & 1.0 \\
\hline Journal website & https://mijn.bsl.nl/meten-van-uitkomsten-van-zorg-met-proms/10101786 \\
\hline Pubmed link & \\
\hline DOI & $10.1007 / \mathrm{s} 12468-016-0014-0$ \\
\hline
\end{tabular}

This is a NIVEL certified Post Print, more info at http://www.nivel.eu

\title{
Meten van uitkomsten van zorg met PROMs
}

\author{
Paul van Kessel , Mattanja Triemstra, Dolf de Boer, Anne Marie Plass \\ NIVEL
}

\section{SAMENVATTING}

Hoe weet je of de zorg effectief is? Hiervoor kun je gebruik maken van zogeheten PROMs (Patient Reported Outcome Measures): vragenlijsten over uitkomsten van zorg, zoals ervaren door patiënten. Dit artikel gaat over wat PROMs zijn, de toepassingsmogelijkheden en over het vinden en selecteren van geschikte PROMs.

Patient Reported Outcome Measures (PROMs) zijn vragenlijsten voor patiënten die de effecten of 'uitkomsten' van de zorg meten. PROMs geven informatie over het resultaat van de zorg of behandeling volgens patiënten. Het gaat dan over hun symptomen, hun fysieke, psychische of sociale functioneren, de ervaren gezondheid of kwaliteit van leven.1) Een uitkomst kan bijvoorbeeld 'lichamelijk functioneren' zijn, gemeten met een item als 'Kunt u zelf uw sokken, kousen of panty's aantrekken?' (uit de Oxford Heupscore). Een ander voorbeeld is zelfzorg, om vast te stellen of iemand uit het ziekenhuis ontslagen kan worden ('Was u bij ontslag uit het ziekenhuis in staat om uw stoma zelf te verzorgen?' uit de CQ-index Stomazorg.2)

\section{TOEPASSING VAN PROMS}

De laatste 10 jaar is er een toenemende belangstelling voor PROMs voor velerlei toepassingen (zie kader Toepassingsmogelijkheden van PROMs). Terwijl PROMs in het verleden vooral werden gebruikt om het effect van een specifieke behandeling te bepalen, worden ze nu steeds vaker toegepast in de spreekkamer of klinische praktijk. Zorgverleners kunnen PROM-vragenlijsten gebruiken voor het evalueren van de zorg en het bijsturen van de behandeling. Om inzicht te krijgen in hoe de gezondheid of het functioneren van patiënten zich ontwikkelt, op individueel niveau en in vergelijking met andere patiënten(groepen). Met PROMs kunnen behandelaren ook de vinger aan de pols houden tussen de consulten door, voor het monitoren van de gezondheid van hun patiënten. Daarnaast worden PROMs gebruikt voor het evalueren en verbeteren van de kwaliteit van zorg, en om de prestaties van zorgaanbieders te meten en te vergelijken. Dit laatste levert informatie op voor diverse transparantiedoeleinden, bijvoorbeeld als keuze- en verantwoordingsinformatie voor patiënten, beleidsmakers en zorgverzekeraars. 
Kessel, P. van, Triemstra, M., Boer, D. de, Plass, A.M. Meten van uitkomsten van zorg met PROMs. Nederlands Tijdschrift voor Evidence Based Practice: 2016, 13(2), 8-10

\section{GENERIEKE OF ZIEKTESPECIFIEKE UITKOMSTEN}

De selectie van de soort uitkomsten en de keuze voor een bijbehorende PROM hangen sterk af van de doelgroep (bij welke patiënten de PROM wordt afgenomen) en het doel van de meting. Een PROM hoeft niet speciaal ontwikkeld te zijn voor een specifieke zorgsector of discipline, want eenzelfde PROM kan in verschillende vakgebieden worden gebruikt. Gaat het om een algemene of heterogene patiëntengroep of is het doel vooral om patiëntengroepen met elkaar te vergelijken, dan ligt een algemene of 'generieke' vragenlijst voor de hand (bijvoorbeeld de EQ5D of SF-36). Betreft het een specifieke patiëntengroep, met een bepaalde aandoening of specifieke beperkingen, dan heeft een ziektespecifieke vragenlijst de voorkeur, omdat die relevante uitkomsten gericht in beeld brengt.3)

Stelregel is dat hoe specifieker de patiëntengroep en hoe specifieker de klachten, hoe specifieker de PROM moet zijn. Zo kan een PROM voor gebruik op een verpleegafdeling van een ziekenhuis heel algemeen zijn (bijvoorbeeld over Algemene Dagelijkse Levensverrichtingen), terwijl de vragenlijst die bij een specifieke patiëntengroep wordt ingezet goed moet aansluiten op de (ziekte)specifieke kenmerken van die doelgroep (bijvoorbeeld de Oxford Heup Score voor patiënten die een heupoperatie hebben gehad). Als eenmaal helder is welke uitkomsten gemeten gaan worden, dan rest de vraag welke PROMs hiervoor beschikbaar en geschikt zijn.

\section{WAAR VIND JE PROMs}

Wanneer de uitkomsten zijn bepaald, is het zaak om bestaande PROMs te inventariseren die deze uitkomsten in kaart kunnen brengen bij patiënten. Dit kan door te zoeken in de bestaande wetenschappelijke literatuur, zoals via PUBMED of door het raadplegen van databases met een overzicht van bestaande PROMs. In tabel 1 staan enkele voorbeelden van databases waarin gezocht kan worden naar PROMs. Vaak volstaat het om zo'n database te raadplegen waarin PROMs zijn opgenomen en geïndexeerd. Hierin kan meestal gezocht worden op type uitkomst en aandoening. Dit levert vaak een grote hoeveelheid bruikbare PROMs op. In korte tijd kunnen hiermee veel bestaande PROMs voor een specifieke uitkomst of aandoening worden geïnventariseerd. Nadeel is wel dat niet alle databases up-to-date zijn, zodat de kans bestaat dat PROMs over het hoofd worden gezien. Dit kan (deels) worden ondervangen door experts te raadplegen.

\section{HOE KIES JE EEN GESCHIKTE PROM?}

$\mathrm{Na}$ het inventariseren van bestaande vragenlijsten dient men een geschikte PROM te selecteren. Want hoewel er voor iedere denkbare uitkomst vaak al veel verschillende PROMs zullen bestaan, zijn niet alle vragenlijsten daadwerkelijk geschikt. Maar hoe kies je nu een geschikte PROM, van goede kwaliteit? Een PROM is geschikt als deze (1) betrekking heeft op uitkomsten die er voor de doelgroep toe doen, en (2) die uitkomsten heel volledig en precies kan meten. Voor de selectie van een PROM moet dus eerst vastgesteld worden welke specifieke uitkomsten van zorg voor patiënten relevant zijn. Het kan hierbij gaan om symptomen (zoals pijn en braken), functioneren (mobiliteit en zelfzorg) of aspecten van kwaliteit van leven (zoals participatie).1) 
Kessel, P. van, Triemstra, M., Boer, D. de, Plass, A.M. Meten van uitkomsten van zorg met

\section{Toepassingsmogelijkheden van PROMs}

PROMs kunnen worden gebruikt als:

1. uitkomstmaat in clinical trials voor het aantonen van effectiviteit van zorg;

2. monitorinstrument in de klinische praktijk of spreekkamer, voor het evalueren en bijstellen van het behandelplan;

3. indicator voor kwaliteit van zorg, als basis voor consumenten-/keuzeinformatie, zorginkoop- en toezichtinformatie.

Er zijn verschillende checklists in omloop die helpen bij het selecteren van een geschikte PROM.6-9) Een belangrijk selectiecriterium is of patiënten betrokken zijn geweest bij de ontwikkeling van de PROM10), want hun betrokkenheid leidt doorgaans tot PROMs die vollediger en preciezer meten.10) Patiënten blijken echter lang niet altijd betrokken te zijn geweest bij de ontwikkeling van PROMs.11) Voorheen werden deze vragenlijsten namelijk vooral door artsen of andere professionals en onderzoekers bedacht en opgesteld. Tegenwoordig is het een 'must' om deze vragenlijsten vooral te baseren op de inbreng van patiënten. Dit kan door middel van patiëntenparticipatie in onderzoek.12, 13) Bijvoorbeeld door middel van focusgroepen, interviews of een Delphimethode onder patiënten.

Verder verdient het de voorkeur om PROMs te gebruiken die uitvoerig zijn getest op begrijpelijkheid en interpretatiewijze. Dit kan met zogeheten cognitieve interviews. 14,15) Hierbij vullen patiënten de vragenlijst hardop denkend in en worden er verdiepende vragen gesteld over de PROM, om de validiteit vast te stellen. Zodoende kan worden vastgesteld of een PROM goed aansluit bij een patiëntengroep en of de vragenlijst meet wat het moet meten. Omdat (officiële) vertalingen ook vaak de plank misslaan - als het gaat om de juiste formulering van vragen, passend bij de essentie van een uitkomst - is het raadzaam om ook vertaalde vragenlijsten eerst nog goed te (laten) valideren bij de patiëntengroep waar de PROM voor wordt gebruikt.16)

Mocht er na de inventarisatie en selectie onverhoopt toch geen geschikte PROM voorhanden zijn, dan is het ook mogelijk om alsnog een specifieke PROMvragenlijst te (laten) ontwikkelen. Zie hiervoor ook de PROMs Handreiking.6)

\section{TOEKOMST VAN PROMS}

Momenteel worden PROMs al veelvuldig toegepast. Landelijke initiatieven betreffen onder meer grootschalig en landelijk gebruik in de ggz (ROM GGZ), systematische afname van PROMs in de orthopedie (LROI) en Meetbaar Beter (voor hartcentra). Daarnaast zijn er nog vele lokale initiatieven, zoals het gebruik van de CaReQoL voor Chronisch Hartfalen 17) door ziekenhuizen en zelfstandige klinieken voor intern gebruik in de klinische praktijk. De verwachtingen van de waarde van PROMs zijn hooggespannen en de ervaringen in de praktijk en nader onderzoek moeten uitwijzen of de beloftes daadwerkelijk worden waargemaakt. 
Kessel, P. van, Triemstra, M., Boer, D. de, Plass, A.M. Meten van uitkomsten van zorg met PROMs. Nederlands Tijdschrift voor Evidence Based Practice: 2016, 13(2), 8-10

\section{LITERATUUR}

1). Wilson IB, Cleary PD. Linking clinical variables with healthrelated quality of life. JAMA 1995;273:59-65.CrossRefPubMed

2). Triemstra M, Asmoredjo J. CQ-index Stomazorg. Kwaliteit van de stomazorg in Nederlandse ziekenhuizen vanuit het perspectief van patiënten. Utrecht: NIVEL; 2013.

3). McKenna SP. Measuring patient-reported outcomes: moving beyond misplaced common sense to hard science. BMC Med 2011;9:86.CrossRefPubMedPubMedCentral

4). Emery MP, Perrier LL, Acquadro C. Patient-reported outcome and quality of life instruments database (PROQOLID): frequently asked questions. Health Qual Life Outcomes 2005;3:12.CrossRefPubMedPubMedCentral

5). Cella D, Riley W, Stone A, Rothrock N, Reeve B, Yount S, et al. The Patient-Reported Outcomes Measurement Information System (PROMIS) developed and tested its first wave of adult self-reported health outcome item banks: 2005-2008. J Clin Epidemiol 2010;63:1179-1194.CrossRefPubMedPubMedCentral

6). van Kessel P, Triemstra M, de Boer D. Handreiking voor het meten van kwaliteit van zorg met Patient Reported Outcome Measures. Utrecht: NIVEL; 2014.

7). U.S. Food and Drug Administration. Guidance for industry: patient-reported outcome measures: use in medical product development to support labeling claims. Health Qual Life Outcomes 2006;4:79.CrossRef

8). Reeve BB, Wyrwich KW, Wu AW, Velikova G, Terwee CB, Snyder CF, et al. ISOQOL recommends minimum standards for patient-reported outcome measures used in patientcentered outcomes and comparative effectiveness research. Quality of Life Research $20131-17$.

9). Terwee CB, van der Wees PJ, Beurskens S. Handreiking voor de selectie van PROs en PROMs. NFU, 2015.

10). Rose D, Evans J, Sweeney A, Wykes T. A model for developing outcome measures from the perspectives of mental health service users. International Review of Psychiatry 2011;23:41-6.CrossRefPubMed

11). Wiering $B$, de Boer $D$, Delnoij $D$. Patient involvement in the development of Patient Reported Outcome Measures: A scoping review. Health Expect 2016.

12). Brédart A, Marrel A, Abetz-Webb L, Lasch K, Acquadro C. Interviewing to develop Patient-Reported Outcome (PRO) measures for clinical research: eliciting patients' experience. Health Qual Life Outcomes 2014;12:15.CrossRefPubMedPubMedCentral

13). Lehoux P, Poland B, Daudelin G. Focus group research and "the patient's view". Soc Sci Med 2006;63:2091-2104.CrossRefPubMed

14). Beatty PC, Willis GB. Research synthesis: The practice of cognitive interviewing. Public Opin Quart 2007;71:287-311.CrossRef

15). Buers C, Triemstra M, Bloemendal E, Zwijnenberg NC, Hendriks M, Delnoij DM. The value of cognitive interviewing for optimizing a patient experience survey. Int $J$ Soc Res Methodol 2014;17:15.

16). el Markhous S, Sixma H, Plass AM. Cognitieve validatie van de VascuQol voor Nederland: de cognitieve validatie van een vragenlijst middels cognitieve interviews bij patiënten met claudicatio intermittens en kritieke ischemie. Utrecht: NIVEL; 2014.

17). van Kessel $P$, Hendriks M, van der Hoek L, Plass AM. Ontwikkeling van de Care Related Quality of Life voor ChronischlHartfalen (CaReQoL CHF). Utrecht: NIVEL; 2015. 


\section{TABLES}

Tabel 1. : Databases met PROMs

\begin{tabular}{|c|c|c|c|}
\hline Database & Initiator & Omschrijving & URL \\
\hline $\begin{array}{l}\text { Meetinstrumente } \\
\mathrm{n} \text { in de zorg }\end{array}$ & $\begin{array}{l}\text { Lectoraat Autonomie en } \\
\text { Participatie van mensen } \\
\text { met een chronische } \\
\text { ziekte, Faculteit } \\
\text { Gezondheidszorg, Zuyd } \\
\text { Hogeschool. }\end{array}$ & $\begin{array}{l}\text { PROMs (veelal } \\
\text { Nederlandstalig) } \\
\text { geïndexeerd op basis } \\
\text { van lichaamsregio, } \\
\text { aandoeningen, } \\
\text { functioneren en auteur }\end{array}$ & $\begin{array}{l}\text { Www. } \\
\text { meetinstrumenten } \\
\text { zorg.nl }\end{array}$ \\
\hline $\begin{array}{l}\text { Belgian } \\
\text { Screening Tools }\end{array}$ & $\begin{array}{l}\text { Universiteit Gent } \\
\text { (verplegingswetenschap) } \\
\text {, Université Catholique } \\
\text { de Louvain \& FOD } \\
\text { Volksgezondheid }\end{array}$ & $\begin{array}{l}\text { Belgisch/Vlaamse } \\
\text { database met } \\
\text { gevalideerde PROMs } \\
\text { die specifiek geschikt } \\
\text { zijn voor de } \\
\text { verpleging, } \\
\text { onderverdeeld in } 24 \\
\text { thema's/domeinen }\end{array}$ & $\begin{array}{l}\text { www.best.ugent. } \\
\text { be }\end{array}$ \\
\hline $\begin{array}{l}\text { Patient-Reported } \\
\text { Outcome and } \\
\text { Quality of Life } \\
\text { Instruments } \\
\text { Database }\end{array}$ & Mapi Research Trust4) & $\begin{array}{l}\text { Grote Franse database } \\
\text { met basisinformatie } \\
\text { over circa } 900 \\
\text { Engelstalige PROMs } \\
\text { in een gratis } \\
\text { toegankelijk deel, en } \\
\text { een betaald deel met } \\
\text { meer gedetailleerde } \\
\text { informatie }\end{array}$ & $\begin{array}{l}\text { Www.proqolid. } \\
\text { org }\end{array}$ \\
\hline $\begin{array}{l}\text { Patient Reported } \\
\text { Outcomes } \\
\text { Measurement } \\
\text { Group }\end{array}$ & University of Oxford & $\begin{array}{l}\text { Een verzameling } \\
\text { reviews voor veel } \\
\text { voorkomende } \\
\text { aandoeningen, waarin } \\
\text { verschillende } \\
\text { (Engelstalige) PROMs } \\
\text { worden beoordeeld op } \\
\text { kwaliteit }\end{array}$ & $\begin{array}{l}\text { http://phi.uhce. } \\
\text { ox.ac.uk/home. } \\
\text { php }\end{array}$ \\
\hline PROMIS & $\begin{array}{l}\text { National Institutes of } \\
\text { Health / Dutch Flemish } \\
\text { PROMIS5) }\end{array}$ & $\begin{array}{l}\text { Een verzameling } \\
\text { items, gegroepeerd per } \\
\text { domein, waarmee } \\
\text { patiënt-gerapporteerde } \\
\text { gezondheidsuitkomste } \\
\text { n en welzijn gemeten } \\
\text { kunnen worden }\end{array}$ & $\begin{array}{l}\text { Www. } \\
\text { dutchflemishpro } \\
\underline{\text { mis.nl }}\end{array}$ \\
\hline
\end{tabular}

